\title{
EFEITOS DE UM TREINAMENTO EM AUTOCONTROLE APLICADO EM OBESOS
}

\author{
Nagela Valadão Cade ${ }^{1}$, Elizeu Borloti² ${ }^{2}$ Andréa Rosalém Vieira e Roriz Perin ${ }^{3}$, Kelly Ambrósio Silveira³ ${ }^{3}$ Ludmila Ferraz³ \\ Margareth Pereira Bergamim ${ }^{4}$
}

\begin{abstract}
RESUMO: Estudo descritivo, de natureza qualitativa, do tipo delineamento experimental intra-sujeito. Verifica o efeito de um Treinamento em Autocontrole (TA) sobre os fatores comportamentais que influenciam o peso corporal e descreve as variáveis que interferem no alcance de metas individuais. O TA foi aplicado em mulheres obesas em tratamento no Programa de Obesidade de um hospital público de Vitória-ES, em 12 sessões grupais semanais. O comportamento de cinco pacientes, das dez que iniciaram o TA, foi analisado, observando-se mudanças favoráveis nas relações sociais, familiares, pessoais e nos estados emocionais. Houve alteração de comportamentos relacionados com perda de peso corporal, com atividade física e comportamento alimentar, que produziram conseqüências discretas na redução do peso.
\end{abstract}

PALAVRAS-CHAVE: Controle comportamental; Educação do paciente; Obesidade; Métodos.

\section{EFFECTS OF A SELF-CONTROL TRAINNING APPLIED TO OBESE PATIENTS}

\begin{abstract}
Descriptive and qualitative study using an intra-subject experimental design. It verifies the effect of selfcontrol training (TA) on the behavioral factors that influence overweight and describes the variables that interfere in reaching the individual goals. The TA was applied to obese women that were patients at an public hospital in Vitória-ES, Brazil, during 12 week group sessions. From 10 patients that enrolled the TA, the behavior of five of them was analyzed. The results points out to favorable changes in familial, interpersonal, and personal relationships and emotions. Behavioral modifications were related to weight loss such as eating behavior and exercises that produced modest consequences on obesity.
\end{abstract}

KEYWORDS: Behavioral control; Patient education; Obesity; Methods.

\section{EFECTOS DE UN ENTRENAMIENTO EN AUTOCONTROLAPLICADO EN OBESOS}

RESUMEN: Estudio descriptivo, de naturaleza cualitativa, del tipo delineamiento experimental intrasujeto. Verifica el efecto de un Entrenamiento en Autocontrol (EA) sobre los factores comportamentales que influyen en el peso corporal y describe las variables que interfieren en el alcance de metas individuales. El EA fue aplicado en mujeres obesas en tratamiento en el Programa de Obesidad de un hospital público de Victoria-ES, en 12 (doce) sesiones grupales semanales. El comportamiento de 5 (cinco) pacientes, de las 10 (diez) que comenzaron el EA, fue analizado, observándose cambios favorables en las relaciones sociales, familiares, personales y en los estados emocionales. Hubo alteración de comportamientos relacionados con la pérdida de peso corporal, con actividad física y comportamiento alimentar, que produjeron consecuencias discretas en la reducción del peso.

PALABRAS-CLAVE: Control comportamental; Educación del paciente; Obesidad; Métodos.

${ }^{1}$ Doutora em Enfermagem. Especialista em abordagem cognitivo-comportamental. Docente do Programa de Pós-Graduação em Atenção à Saúde Coletiva e do Curso de Graduação em Enfermagem da Universidade Federal do Espírito Santo-UFES.

${ }^{2}$ Pós-Doutor em Psicologia Experimental. Especialista em abordagem cognitivo-comportamental. Docente do Programa de Pós-Graduação em Psicologia da UFES.

${ }^{3}$ Alunas dos cursos de Graduação em Enfermagem e Psicologia da UFES.

${ }^{4}$ Mestranda do Programa de Pós-Graduação em Psicologia da UFES.

Autor correspondente:

Nagela Valadão Cade

Av. Marechal Campos 1468 - 29040-090 - Vitória-ES.

Recebido: 11/11/08

E-mail: nagelavc@terra.com.br

Aprovado: 24/03/09 


\section{INTRODUÇÃO}

No Brasil, nos últimos quinze anos, a obesidade aumentou $100 \%$ nos homens e $70 \%$ nas mulheres. Aproximadamente um terço da população americana é de obesos, e essas cifras vêm aumentando ${ }^{(1-2)}$. A obesidade, além de ser uma doença, é um dos principais fatores de risco para doenças crônicas não transmissíveis, como hipertensão, doença cárdio e cerebrovascular e diabetes, contribuindo para o perfil de morbi-mortalidade brasileira. Também pode gerar sofrimento psicossocial, pois a cultura predominante privilegia a magreza e isso faz com que pessoas obesas carreguem o estereótipo do relapso e da falta de força de vontade ${ }^{(3)}$.

A obesidade é multiderterminada pela interação entre estilo de vida, biologia do indivíduo, ambiente psicossocial e fatores econômicos. Essa etiologia múltipla define formas de tratamento, realizadas, preferencialmente, em equipe constituída por dieticistas, enfermeiros, médicos, treinadores físicos, psicólogos ou voluntários de apoio ${ }^{(3)}$. Para aqueles com dificuldade para perder peso ou com comorbidades fisiológicas, é indicado tratamento farmacológico ou cirúrgico ${ }^{(2)}$. Entretanto, o tratamento mais recomendado para a obesidade focaliza a alimentação e a prática de atividade física, a partir do levantamento do perfil comportamental do paciente, visando ao apoio psicológico, à educação nutricional e à monitorização rumo a um novo estilo de vida ${ }^{(3)}$.

Diretiva e orientada para um objetivo numa situação-problema, a abordagem cognitivocomportamental tem sido utilizada eficazmente para instalar e manter um repertório benéfico ao alcance de metas realistas para reduzir a obesidade ${ }^{(4-5)}$. A partir da manipulação das variáveis que controlam o repertório que mantém o ganho de peso, é possível modificar indiretamente o peso corporal ${ }^{(6)}$. Faz-se isso, mudando contingências (relações entre eventos e comportamentos) e regras (valores e crenças) que governam os comportamentos. O paciente planeja suas metas, discute, escolhe e implementa os meios para atingi-las de acordo com recursos disponíveis, aumentando o seu o nível de autocontrole ${ }^{(7)}$. Trata-se de um processo de aprendizagem que pode ser adquirido por meio de treinamento.

As bases do Treinamento de Autocontrole (TA) encontram-se na abordagem comportamental operante.

[...] o controle do próprio comportamento ocorre quando um comportamento (autocontrole ou resposta controladora) tem como conseqüência a modificação de elementos de contingências que determinam comportamentos subseqüentes (resposta controlada) ${ }^{(8: 15)}$.

O controle instrucional opera no processo de autocontrole no sentido em que as instruções ou autoinstruções atuam na escolha entre duas alternativas de reforço: para perder peso, o obeso deve escolher entre uma alternativa imediata e outra mais atrasada. A escolha pelo imediato define a impulsividade e a compulsão; a escolha pelo atrasado define o autocontrole.

O TA atua na geração de contingências ambientais que alteram a probabilidade da resposta “controlada”. Isso significa: a) manipular estímulos discriminativos (pessoas ou lugares que predispõem o comer em excesso); b) criar operações estabelecedoras da motivação (com alimentos ricos em fibras, por exemplo); c) modificar a probabilidade de ocorrência de elementos reforçadores/punidores (definindo uma meta exeqüível); ou d) descrever respostas alternativas que não impliquem punição (avaliar um percurso que deu "errado", ao invés de culpar-se).

Desde a década de 60, o TA tem sido considerado um tratamento eficaz, a despeito dos seus resultados modestos sobre o peso corporal, pois as variações nos TAs para a redução do peso corporal indicam uma melhor compreensão das variáveis envolvidas na condição da obesidade ${ }^{(9)}$. É por essa razão que as intervenções cognitivo-comportamentais atuais mudaram de foco. Passaram a focar a manutenção do peso e a mudança no estilo de vida. Com isso, os terapeutas têm modificado a sensação do obeso de imprevisibilidade da perda de peso e garantido um alvo mais acessível: a mudança de comportamento ${ }^{(3)}$.

Com essa justificativa e prevendo um resultado modesto sobre o peso corporal, o TA foi a técnica empregada neste estudo, pois o obeso, à medida que se comporta, também pode observar, avaliar e modificar seu comportamento. Esse fato é idiossincrático e, por essa razão, torna-se relevante conhecer as variáveis que afetam o autocontrole de cada obeso. Portanto, este estudo tem os seguintes objetivos: verificar o efeito do TA sobre os fatores comportamentais que influenciam o peso corporal; conhecer e descrever as variáveis que interferem no alcance das metas individuais; e descrever a alteração de peso durante o TA, relacionando-a com a mudança comportamental. 


\section{MÉTODOS}

Estudo observacional, descritivo, do tipo delineamento experimental intra-sujeito, sendo o grupo submetido à intervenção seu próprio controle, fornecendo a medida do peso corporal pré e pósintervenção para serem analisadas e comparadas.

A amostra constituiu-se de dez mulheres atendidas no Ambulatório de Obesidade de um hospital público em Vitória-ES, que freqüentaram pelo menos duas consultas com o nutricionista e duas com o endocrinologista, ou que mantiveram freqüência ao programa para obesidade por, no mínimo, seis meses. Excluíram-se as pacientes com obesidade mórbida (IMC $\geq 40,0$ ).

Quanto aos procedimentos, submeteu-se o projeto ao Comitê de Ética da Universidade e foram selecionados seis alunos de graduação - Psicologia e Enfermagem - para participar da seleção das pacientes e atuar como acompanhantes terapêuticos no monitoramento dos comportamentos necessários à adesão ao tratamento e redução do peso corporal.

Utilizou-se um roteiro de entrevista compreendendo questões relacionadas com o sobrepeso: seqüelas psicossociais, história e tratamento, padrão e topografia alimentar, fatores comportamentais que influenciam a alimentação, padrões de atividade, rede de suporte social e medicações utilizadas.

A intervenção proposta constituiu o TA adaptado do modelo de Schmidt( ${ }^{(10)}$ e foi conduzida em 12 sessões semanais grupais. As sessões objetivaram integrar o grupo e partilhar a avaliação e a resolução das dificuldades durante o processo de autocontrole. A estrutura das sessões permitiu abordar os temas: motivação, autocontrole, definição e avaliação de metas; auto-observação de antecedentes e conseqüentes ao comportamento relevante (alimentar e de exercício físico), auto-reforço, contrato de contingência (estabelecimentos de conseqüências para a emissão de comportamentos-meta), autocontrole do pensamento, auto-estima e recaída.

Os dados foram coletados entre maio e outubro de 2004. Todas as sessões foram gravadas e transcritas e identificadas com codinomes (Maria 1...; Maria 2...).

As pacientes auto-observaram o seu comportamento no seguimento da prescrição dietética e de exercícios físicos (caminhadas) e receberam suporte técnico de um acompanhante terapêutico responsável pelo reforço da adesão, observação de comportamentos em ambiente natural, apoio emocional e instrução. Além disso, receberam um diário de autocontrole no qual escreviam as tarefas de casa e comentários livres.

\section{RESULTADOS E DISCUSSÃO}

Dez mulheres foram selecionadas. Duas freqüentaram apenas três sessões e, das oito que se mantiveram no grupo, três faltaram mais de $60 \%$, o que não permitiu a análise destes dados. Dessa forma, somente cinco pacientes permaneceram no estudo.

Quanto à caracterização, a idade variou de 36 a 60 anos e tinham escolaridade baixa. Somente uma trabalhava como autônoma em cooperativa e as demais eram do lar, sendo uma aposentada. Três apresentavam obesidade grau I e duas pacientes, grau II, associada à hipertensão arterial e diabetes mellitus tipo 2.

Quatro delas faziam uso de medicamentos que inibem o apetite e uma também usava fluoxetina (agente sacietógeno e antidepressivo). Associavam a obesidade à perda da agilidade, cansaço, dor nas articulações e costas, limitação física e insatisfação com a auto-imagem. Diziam que o aspecto positivo do emagrecimento é a elevação da auto-estima, a disposição para trabalhar, a sensação de corpo leve e saúde melhor e a gratificação de poder vestir roupas menores. Como aspecto negativo da obesidade, citaram a discriminação de vizinhos e familiares e a pressão para emagrecer por médicos, familiares e amigos.

Quanto aos comportamentos benéficos ao controle da obesidade, somente duas delas faziam caminhadas regularmente.

Como topografia alimentar, consumiam uma dieta normal, sem carboidrato simples. Somente Maria 3 falou sobre a quantidade da ingestão, aprendida no seguimento da dieta para controle do diabetes. Reconheceram que, às vezes, comem demais. Todas relataram que fazem três refeições diárias, omitirem o lanche da tarde ou o jantar e afirmaram que comem muito rápido, ora em pé, sozinhas e, por vezes, assistindo à televisão. Ao comerem muito, geralmente apresentavam ansiedade, raiva, tristeza, aborrecimento, culpa, arrependimento, preocupação, sensação de estômago inchado e mal-estar.

Uma vez que a perda do peso corporal não era o foco principal do TA, a discussão centra-se na análise das variáveis associadas à presença ou à ausência de mudança comportamental em cada caso. Assim, segue no Quadro 1, o peso das pacientes e a seguir uma 
discussão dos casos, acompanhada de um parecer conclusivo.

Quadro 1 - Peso corporal (kg) das pacientes antes e depois do Treinamento em Autocontrole

\begin{tabular}{|lll|}
\hline Pacientes & \multicolumn{2}{c|}{ Peso corporal (kg) } \\
& antes do TA & depois do TA \\
\hline Maria 1 & 106,700 & $104,200(-2,3 \%)$ \\
Maria 2 & 84,00 & Não obtido \\
Maria 3 & 79,900 & $79,700(-0,2 \%)$ \\
Maria 4 & 83,100 & $84,400(+1,6 \%)$ \\
Maria 5 & 78,500 & $77(-1,9 \%)$ \\
\hline
\end{tabular}

Maria 1 (54 anos, um filho casado que reside em outro Estado, mora com um irmão divorciado, aposentada, diabética, hipertensa, cardiopata). À época do TA, ela fazia trabalhos manuais, vendia e usava medicamentos "naturais”. Tinha indicação para cirurgia bariátrica, evento que a preocupava pela falta de suporte social no período pós-operatório. Sentia saudades das amigas de São Paulo, mas não tinha condições financeiras para viajar. Apesar de ter uma família numerosa, o contato estava restrito devido a atritos passados. Relatou desamparo, solidão e mágoa, e a experiência passada levava-a a desconfiar de familiares e amigos atuais. Tal variável teve relação com as suas expectativas com o TA:

\section{Espero que bons amigos saiam daqui (Maria.1).}

Gostava de alimentos hipercalóricos associados aos contatos sociais que diminuíam a solidão e aumentavam a autoconfiança. Acreditava que seu sobrepeso independia do seu comportamento. Como "benzedeira”, influenciava as pessoas com um saber popular sobre saúde e tal comportamento era fortemente reforçado pela comunidade, garantindo-lhe respeito e credibilidade. Mostrou resistência ao seguimento de regras alheias: ela sabia o que era bom para sua própria saúde. Se a instrução sobre os comportamentos em saúde fosse formulada por ela, ela a seguia; se formulada por outros, não. A variável falta de suporte social pós-cirúrgico atuou na decisão de não se submeter à cirurgia bariátrica. Também depreciava instruções sobre maneiras de se autocontrolar e descumpria as tarefas propostas durante o TA.
De uma ou de outra forma, pacientes obesos podem seguir regras apresentadas por médicos e nutricionistas, como também formular e seguir regras próprias em função da sua experiência cotidiana (as chamadas auto-regras). Em qualquer caso, regras e auto-regras podem ser explicitadas publicamente ou ocorrerem de forma encoberta ou "em pensamento"(11).

Contradições entre relatos telefônicos e ao vivo mostraram pouca correspondência entre dizer e fazer, podendo sugerir uma sensibilidade às contingências, a despeito das regras, ${ }^{(12)}$ pois Maria 1 apresentou 100\% de freqüência e chegou antes do início de todas as sessões.

Apesar do não engajamento nas atividades que a levariam à mudança, foi a participante que mais perdeu peso. Esse fato sugere que Maria 1 pode ter contatado contingências que mostraram incongruência com as auto-regras que guiavam alguns dos seus comportamentos, levando à perda de peso. Na avaliação final, relatou que conseguiu parar de ingerir leite achocolatado, mudança reforçada no repertório de autocontrole a partir das poucas metas objetivas que estabeleceu.

O significado dos vínculos afetivos gerados no grupo como suporte parece ter influenciado seu vestuário, pois trocou as roupas de tecido pesado, estilo militar, por outras de tecido leve, bordado e com brilho. Presenteou sua acompanhante terapêutica e, após o término do TA, telefonou para um dos terapeutas para falar da vida e do grupo. Esse fato sugere o processo grupal como uma variável importante na mudança objetivada no TA para obesos ${ }^{(9,13)}$.

Em resumo, não foi possível discriminar com exatidão quais comportamentos podem ter favorecido a perda de peso, sejam aqueles reforçados no TA, sejam em outros contextos. Entretanto, é possível inferir que $\mathrm{o}$ alcance das metas individuais foi mediado por auto-regras sobre as relações comportamento-saúde, e as metas pareceram ser seguidas apenas quando traçadas por ela. Possivelmente, a quantidade de instruções que lhe foram dadas pelas demais pacientes, por solicitação dos terapeutas, podem, como alternativas de comportamento, ter favorecido a sensibilidade às contingências da perda de peso, a despeito de uma aparente recusa em segui-las.

Maria 2 (36 anos, casada, dois filhos, cozinheira). Cozinheira cooperada, durante o TA, cuidava de dois meninos, ficando sem tempo para a família. A ocupação e o contato com muitos itens alimentares era uma variável importante no aumento 
da probabilidade de emissão de comportamentos favoráveis ao sobrepeso, pois, no trabalho, ela provava e comia os alimentos que preparava. Expressou com a TA o desejo:

\section{[...] fazer amizades e ter força para emagrecer (Maria.2).}

Pensava com freqüência num irmão que morrera há quatro meses, o que a fazia chorar. Numa sessão, verbalizou:

\section{Decidi parar de chorar, dar um basta (Maria.2).}

Tristeza e culpa pela falta de familiares acompanhavam de modo persistente certos comportamentos: abusou de álcool no bar que o irmão freqüentava, viu televisão até três horas da madrugada, faltou ao trabalho para ficar com os filhos.

A comida era um elemento reforçador com funções também afetivas: uma das formas de celebração de um raro encontro familiar. Precisava, com freqüência, dizer à família:

Vou ficar em casa com vocês, vou fazer uma comidinha gostosa (Maria.2).

A contingência da distância da família, que adquiriu um significado peculiar após a morte do irmão, gerava ansiedade que se reduzia como efeito do seu comportamento alimentar. Quando eles não estavam por perto, o comer era inadequado, de pé e rápido, geralmente diante de uma televisão ligada. Quando por perto, solicitavam (e ajudavam) que fizesse guloseimas. Após auto-observar-se, concluiu que tristeza e/ou culpa acompanhavam o comportamento de beliscar guloseimas.

Decidiu comer frutas e legumes em horários definidos e pediu a uma colega para lembrá-la da meta de não beliscar alimentos no trabalho. Sugestões do grupo para que ela obtivesse melhores resultados em frente à meta escolhida sempre eram acompanhadas por comentários que atestavam uma auto-exigência:

Se me lembrarem que estou comendo, fico nervosa. Tenho que tomar as decisões por mim mesma; não posso me sentir pressionada (Maria.2).

De fato, ela estava sob controle da contingência da distância da família da qual se aproximava por meio de refeições calóricas. Isso competia com o seguimento das instruções dadas no TA, levando-a a descrever sua condição como "pressionada".

As variáveis ambientais continuaram a atuar sobre o comer excessivo durante o TA. A doença e o internamento da mãe sinalizaram outras perdas, gerando ansiedade, que foi reduzida com o descumprimento da meta traçada para o autocontrole do comer.

Na sessão final de avaliação, relatou substituir itens do jantar, consumir leite desnatado com fibras e comer mais verduras, sentindo-se saciada, o que não ocorria antes. Relatou ter estabelecido um contrato de contingência (uma definição de uma relação entre eventos ambientais - antecedentes e conseqüentes e comportamentos saudáveis), mesmo não o tendo discutido no grupo. Possivelmente, como esperado num grupo, seguiu instruções aprendidas pelo modelo das outras pacientes, generalizando os comportamentos das outras para si própria. Isso aponta a importância de alguns mecanismos do grupo como variáveis no controle de comportamentos favoráveis à perda de peso: a identificação de problemas com as demais soluções mais factíveis para o contexto da própria paciente, o comportamento imitativo mediante a observação do comportamento das outras pacientes (aprendizagem vicária ou por modelação) ${ }^{(14)}$.

Mesmo não cumprindo as metas iniciais, generalizou as estratégias para outros comportamentos, geralmente, acompanhados por tristeza ou culpa. Mudou em relação à morte do irmão e à distância da família. Discriminou o contexto ambiental funcional ao sobrepeso (relações emoções-comer). Seus relatos nas sessões indicaram que ela passou a perceber as contingências favorecedoras do sobrepeso. $O$ contato preciso com as relações comportamento-emoção-peso favoreceu um controle instrucional útil à manutenção de comportamentos saudáveis.

Maria 3 (60 anos, casada, mora com o marido e o filho único, doméstica, hipertensa, diabética). Apresentava como expectativa com o TA emagrecer e manter o diabetes controlado. Desejou retornar ao peso ideal (60 kg) mastigando bem os alimentos, em horários definidos. Também escreveu como metas: diminuir os pensamentos negativos acompanhados de choro, solidão e "vazio" (que ocorriam quando o marido e o filho saíam para trabalhar) e evitar a ingestão de doces e refrigerantes em festas. Decidiu ouvir música evangélica, para relaxar, e comer verduras, frutas e legumes em cinco dias da semana.

Relatou, por várias vezes, o alcance de suas 
metas: mastigar bem os alimentos, caminhar diariamente e não comer nas festas que participava. Em uma sessão, relatou uma estratégia aprendida para o controle dos estímulos para o comer em excesso:

Pensei em fazer coisas para comer, mas pensei: não vou fazer nada, porque se eu fizer, eu vou comer. Não fiz mesmo (Maria.3).

Outros relatos envolveram o manejo do sono, da respiração e uma surpresa com o corpo:

Toda semana eu tenho que apertar as roupas [...]. Meu manequim era 52 e agora é 46 (Maria.3).

O Marido e o filho reforçavam comportamentos facilitadores da perda de peso. O filho "policiava" o comer devagar e ambos aceitavam o cardápio restrito da casa. A religião evangélica constituía um suporte social importante em sua vida.

Sua adesão ao TA pode ter sido uma generalização da adesão ao tratamento do diabetes, pois apresentava um autoconhecimento importante sobre a doença, no que diz respeito ao controle alimentar e aos estados emocionais associados à glicemia. Discriminava o contexto ambiental para a preocupação e a solidão e valorizava distração e relaxamento como modos de enfrentamento. Já iniciara o TA com um repertório de autocontrole desenvolvido, seguindo regras já aprendidas, mesmo que errôneas em alguns aspectos (por exemplo, substituir a janta de baixa caloria por um lanche de alta caloria). Apesar da discreta perda de peso, o ganho maior do seu processo de autocontrole foi a generalização dos procedimentos para o manejo da preocupação e da solidão na vida.

É possível inferir que a história de vida dessa paciente, que decidiu seguir instruções para o manejo do diabetes e para a vivência da religiosidade, fez com que seu padrão de seguimento se mantivesse estável diante das exigências do TA. Entretanto, algumas vezes, essa paciente descrevia discrepâncias entre as regras que seguia e as contingências experimentadas, confirmando os achados de Madden, Chase e Joyce ${ }^{(21)}$ sobre a manutenção de regras equivocadas. Ela passou a seguir uma regra errônea referente à substituição de refeições: parou de jantar, mas passou a consumir uma refeição de alta caloria, entendida como de baixa caloria. De forma evidente, para ela, a diferença entre lanche e jantar estava na quantidade ingerida e não no valor calórico dos alimentos.
Maria 4 (44 anos, doméstica, casada, dois filhos adolescentes, hipertensa). Quis reduzir e manter o peso e sua meta inicial foi melhorar a auto-estima. Depois, pontuou outras metas, como realizar caminhada quatro vezes por semana, comer verduras diariamente e abolir o açúcar.

Ao longo das sessões, comportou-se favoravelmente à perda de peso: parou de jantar, reduziu a ingestão exagerada de carne, mastigou adequadamente e caminhou diariamente uma hora. Explicitou que o marido passou a comer menos e perder mais peso do que ela. Ele, ainda, a incentiva a reduzir a ingestão de alimentos. Uma possível indicação de mudança na auto-estima ficou evidente numa determinada sessão, quando veio com os cabelos soltos, sendo elogiada pelas colegas do grupo.

Para reduzir a preocupação com a filha adolescente que apresentava desinteresse em estudar e em trabalhar, empregou estratégias de resolução de problema sugerida pelo grupo, procurando ajuda profissional para a filha. As estratégias de mudança de contingências para o TA da obesidade ajudaramna a diminuir a irritação e o incômodo na interação com a filha.

Uma análise preliminar mostra que ela chegou ao grupo com metas indiretamente relacionadas com a redução de peso, demandadas pelo baixo reforçamento social positivo e pelo excesso de controle aversivo que mantinham a baixa auto-estima e o humor depressivo ${ }^{(15-16)}$.

O grupo parece ter funcionado como um suporte social que, antes, não existia. Nesse sentido, minimizou o impacto negativo do ambiente social sobre a paciente Estudos evidenciam a relação da percepção quanto a ter suporte com a melhora de emoções negativas, como tristeza e ansiedade ${ }^{(17)}$. O suporte social para os obesos aumenta a adesão aos tratamentos e fortalece a manutenção da perda do peso; o contrário se observa naqueles obesos sem suporte social ${ }^{(13)}$.

Possivelmente, devido a essa variável, o processo grupal ajudou-a a mudar o modo de pensar, sentir e agir na relação com a filha e consigo mesma. Conseguiu que o marido fosse um suporte social. Relatou mudanças de hábitos importantes na redução de peso, como caminhar, eliminar refeições e demorar a mastigação. Essa possível relação entre eventos sugere a influência do controle familiar sobre a baixa auto-estima e o humor depressivo e o quanto o processo grupal pode ter sido útil na modificação desses estados emocionais ${ }^{(16)}$.

Apesar de todos esses relatos de mudança, ela 
ganhou $4 \mathrm{~kg}$ nas primeiras oito semanas do TA. Depois, nas quatro semanas seguintes, perdeu $2,7 \mathrm{~kg}$, mantendo ganho ponderal de 1,3 kg em relação ao início.

Maria 5 (41 anos, doméstica, casada, dois filhos adolescentes). Desejou retornar ao peso de antes de engordar. Apresentou como meta inicial caminhar e modificar o lanche da tarde. Ao longo das sessões, relatou mudanças favoráveis nessa direção: caminhava e não ingeria pães à tarde. Após autoobservar-se, passou a evitar os ambientes (casas de parentes) que atuavam como estímulos discriminativos para a ingestão de alimentos hipercalóricos ${ }^{(18)}$.

Apesar de não ter sido uma meta, voltou a dirigir automóvel após longo período de esquiva fóbica de direção, acompanhada de críticas conjugais, fato que a deixava "chateada". Ao relatar semelhanças entre o TA e o processo que ela empregou para começar a dirigir, pôde-se verificar uma generalização da aprendizagem dos componentes do TA para o manejo da fobia de direção.

Ela se mostrou sensível ao seguimento de instruções alheias, o que sugere uma variável importante para o alcance do benefício do TA. Isso pode ser inferido diretamente dos seus relatos. Pessoas reforçavam suas caminhadas. Mãe e marido tornaram-se parceiros: 0 marido a incentivava a caminhar com a mãe, que a levava à prática desse exercício. Relatos sobre o comportamento dele indicam desmembramentos da sua ação controladora: sinalizava excessos alimentares, comprava roupas novas em caso de perda de peso. Apesar de desafiá-la, duvidando da decisão de perder peso, seu suporte pareceu importante no cumprimento das metas específicas. Ela caminhou e envolveu pessoas nessa atividade, substituiu/eliminou refeições/nutrientes, generalizou estratégias para outros comportamentos (dirigir), identificou e esquivou-se de ambientes favoráveis à obesidade.

Apesar da expectativa de perda rápida do peso, emitiu um repertório que poderá manter a perda de peso. Como em outros casos, o suporte social familiar foi uma variável importante na adesão ao TA, podendo continuar a atuar na manutenção da perda do peso ${ }^{(13)}$. Com tal suporte, a paciente seguiu instruções para o autocontrole: aumentava a freqüência das caminhadas de modo gradual e isso alterava o nível de motivação para a atividade.

\section{CONSIDERAÇÕES FINAIS}

Ao final do TA, percebeu-se que houve alteração nos comportamentos das cinco pacientes analisadas. Houve mudanças nas relações sociais, nas relações familiares, nas relações pessoais e nos estados emocionais desagradáveis. Além disso, percebeu-se que o autocontrole afetou outras esferas da vida das participantes. O que era, no princípio, uma proposta dos pesquisadores para a mudança de comportamentos relacionados com a obesidade serviu para responder a outras demandas - resolver problemas de assertividade na família, de ansiedade, de pensamentos intrusivos, de fobia de direção, de tomada de decisões.

Quanto aos efeitos modestos do TA sobre o peso corporal, este estudo confirma os resultados de outros, quando analisam o significado numérico das estratégias cognitivo-comportamentais sobre a perda do peso corporal $^{(15)}$. Entretanto, uma análise qualitativa do controle de contingências e de instruções sobre comportamentos favorecedores da perda de peso corporal permitiu uma compreensão das variáveis envolvidas no alcance das metas pelos, pacientes e do que pode ser feito para garantir mudanças no estilo de vida que produzirão conseqüências em longo prazo. Essas variáveis deverão ser consideradas em quaisquer tipos de intervenções sobre a obesidade. Sugere-se que, apesar das dificuldades de adesão, tratamentos de longa duração poderiam reforçar as mudanças no estilo de vida e verificar os efeitos dessa mudança sobre o peso corporal.

\section{REFERÊNCIAS}

1. Lessa I. Obesidade. In: O adulto brasileiro e as doenças da modernidade. São Paulo: Hucitec/Abrasco; 1998.

2. Sarwer DB, Wadden TA. The treatment of obesity: what's new, what's recommended. J Womens Health Gen Based Med. 1999; 8(4): 483-93.

3. Brownell KD, O’Neil PM. Obesidade. In: Borlow DM, organizador. Manual clínico dos transtornos psicológicos. Porto Alegre: Artmed; 1999.

4. Kaukua J, Pekkarinen T, Sane T, Mustajoki P. Healthrelated quality of life in obese outpatients losing weight very-low-energy diet and behaviour modification: a 2year follow up study. Int J Obes Rel Metab Disod. 2003; 27(9): 072-80.

5. Lantz H, Peltonen M, Agren L, Torgerson JS. A dietary and behavioural programme for the treatment of obesity. A 4 year clinical trial and a long-term 
posttreatment follow-ap. J Int Med. 2003; 254(3): 272-9.

6. Wadden TA, Butryn ML. Behavioral treatment of obesity. Endocrinol Metab Clin North Am. 2003; 32(4): 981-1003.

7. Blair T. Integration and synthesis: cognitive behavioral therapies within the biological paradigm. J Psychos Nurs. 1996; 34(12): 26-31.

8. Hanna ES, Ribeiro MR. Autocontrole: um caso especial de comportamento de escolha. In: Josele Abreu Rodrigues, Michela Rodrigues Ribeiro, organizadores. Análise do Comportamento: Pesquisa, Teoria e Aplicação. Porto Alegre: Artmed; 2005.

9. Heller DCL, Kerbauy RR. Redução de peso: identificação de variáveis e elaboração de procedimento com uma população de baixa escolaridade. Revista Brasileira de Terapias Comportamental e Cognitiva 2000; 2(1): 31-52.

10. Schmidt JA. Ajude-se a si mesmo: um guia para a automodificação. São Paulo: Cultrix; 1976.

11. Jonas AL. Regras e auto-regras no contexto terapêutico. Integração, São Paulo; 2004.

12. Madden GJ, Chase PN, Joyce JH. Making sense of sensitivity in the human operant literature. The Behavior Analyst 1998. 21: 1-12.

13. Wing RR, Feffery RW. Benefits of recruiting participants with friends and increasing social support for weight loss and maintenance. J.of consulting and clin paychology 1999; 67(1): 132-8.

14. Vinogradow S, Yalom ID. Guia breve de psicoterapia de grupo. Barcelona (BCN): Paidós; 1996.

15. Seligman A. The Problem of Trust. Princeton: Princeton University Press; 1997.

16. Lewinsohn PM, Sullivan JM, \& Grosscup SJ. Changing reinforcing events: An approach to the treatment of depression. Psychotherapy: Theory, Research, and Practice 1980. 47: 322-34.

17. Oxman TE, Hull JG. Social support and treatment response in older depressed primary care patients. J Gerontol B Psychol Soc Sci 2001; 56 (1): 35-45.

18. Abreu-Rodrigues J, Beckert ME. Autocontrole: pesquisa e aplicação. In: Abreu CN, Guilhardi HJ, organizadores. Terapia Comportamental e Cognitivo-Comportamental: Práticas Clínicas. São Paulo: Roca; 2004. p. 259-74.

Cogitare Enferm 2009 Jan/Mar; 14(1):65-72 